\title{
Synthesis of Ceria Nanosphere by Ultrasonic Spray Pyrolysis
}

\author{
Jong Young Kim ${ }^{\dagger}$, Ungsoo Kim, and Woo-Seok Cho \\ Korea Institute of Ceramic Engineering and Technology, Icheon 467-843, Korea \\ (Received February 6, 2009 ; Revised March 16, 2009 ; Accepted March 18, 2009)
}

\begin{abstract}
Nanocrystalline ceria particles were prepared by using the ultrasonic spray pyrolysis method. The prepared ceria particles were found to be spherical and non-agglomerated by the SEM and TEM analyses. It was found that carrier gas influences the size and morphology. It was found that the air stream of carrier gas results in porous agglomerated structure of ceria abrasives, whereas solid nano-sphere can be obtained in a more oxidizing atmosphere.
\end{abstract}

Key words : Ceria, Abrasive, Spray pyrolysis, Spherical particle

\section{Introduction}

C eria $\left(\mathrm{CeO}_{2}\right)$ is an important abrasive material especially for glass and $\mathrm{SiO}_{2}$ polishing for display and semiconductor devices. This material's importance is especially true for the CMP (Chemical Mechanical Planarization) application in the semiconductor industry. As the feature dimension shrinks below $100 \mathrm{~nm}$, ceria CMP slurry becomes more important because CMP scratches due to abrasive significantly influences the yield of semiconductor device. Recently, the concept of spherical and porous ceria abrasive is emerging because the hardness and sharp facet of abrasive can be scratch sources. Therefore, there has been an effort to get porous and spherical ceria particles as well as to eliminate abnormally large particles by classification.

Porosity plays an important role in the scratch issue. Abrasive composed of small microcrystals by agglomeration is known to show better performance in scratch performance than in conventional methods. ${ }^{1)}$ Controlling the porosity of ceria abrasive by USP (Ultrasonic Spray Pyrolysis) was the goal of this study, which might be useful for scratch reduction in the CMP process. If the morphology of porous agglomerate is partly induced, especially for larger particles in size distribution, the porous abrasive can be broken into small ones under the down force in CMP process, which results in scratch reduction.

Ceria particles can be prepared by using various techniques such as mechanochemical process, ${ }^{2)}$ hydrothermal synthesis, ${ }^{3)}$ microemulsion, ${ }^{4}$ jet milling, ${ }^{5)}$ and sol-gel methods. ${ }^{6)}$ However, it is still challenging to get an abrasive without having a sharp facet and edge. Feng et al. obtained

\footnotetext{
${ }^{\dagger}$ Corresponding author: Jong Young Kim

E-mail : jykim@kicet.re.kr

Tel : +82-31-645-1423 Fax : +82-31-645-1486
}

spherical ceria particle by using the liquid flame pyrolysis technique, but doping of titanium is required. ${ }^{7}$ The synthetic method by $\mathrm{Xu}$ et al. $^{8)}$ requires additional equipment to obtain spherical solid ceria and its particle size is large for CMP abrasive which means that a diameter of $\sim 100 \mathrm{~nm}$ is needed. In this study, the preparation conditions to get spherical solid ceria abrasive by using ultrasonic spray pyrolysis synthesis was investigated.

\section{Experimental Procedure}

\subsection{Preparation of powder}

The ceria powder was prepared by using an ultrasonic spray pyrolysis. Cerium acetate hydrate (Aldrich 99.9\%; $1.5 \%$ or $0.15 \%$ ) was dissolved in water and mixed with ethanol.(1:2 W/EtOH) The precursor solution was sprayed into fine mist by using a conventional ultrasonic nebulizer with a resonant frequency of $1.65 \mathrm{Mhz}$. The dry air stream or $\mathrm{Ar} / \mathrm{O}_{2}$ flow of $2 \mathrm{~L} / \mathrm{min}$ carried the mist into a high temperature tubular quartz reactor. The length and diameter of reactor were $1000 \mathrm{~mm}$ and $70 \mathrm{~mm}$, respectively. The mist was ignited by a 3-zone furnace, which led to combustion of metal precursor and generation of cerium oxide particles. The ceria powder in the stream was collected into the powder collector. (Please refer to supplementary information for more information about the equipment.)

\subsection{Characterization of sample}

The obtained samples were examined by XRD (X-ray diffraction), TEM (Transmission Electron Microscopy), and SEM (Scanning Electron Microscopy). Powder XRD patterns were recorded at room temperature on a Rigaku RINT-2000 diffractometer with a $\mathrm{CuK} \alpha$ radiation source. Xray tube voltage and current were at $40 \mathrm{kV}$ and $100 \mathrm{~mA}$, respectively. High resolution TEM experiments were conducted using an electron microscope (model JEM-4010; JEOL Ltd., Tokyo, Japan), operating at an accelerating vol- 
atage of $400 \mathrm{kV}$. A drop of sample solution, in which powder was dispersed in ethanol, was placed onto a 300-mesh copper grid coated with carbon. Field Emission-SEM images were obtained with JSM-6701F (JEOL Ltd) with an accelerating voltage of $15 \mathrm{kV}$. The samples were prepared by attaching the powder to the carbon adhesive, which was coated with platinum by sputtering.

\section{Results and discussion}

The spray pyrolytic method was effectively applied to nanoparticle synthesis because the produced ceramic particles had narrow size distributions, uniform shapes, and controlled purity. ${ }^{899}$ In addition, there are the advantages in the manufacturing process such as simple operation, continuous process, easy control of chemical uniformity and stoichiometric composition in multi-component metal oxides. Pyrolytic method, however, has a drawback of its own porous structure formation because of insufficient solute diffusion and particle densification due to its fast evaporation rate. Because of the solute concentration gradient created during the evaporation of droplets, the precipitation of solute occurs first at the supersaturated surface when time for solute diffusion in droplet is not available. It was also discovered that experimental conditions in large scale synthe-

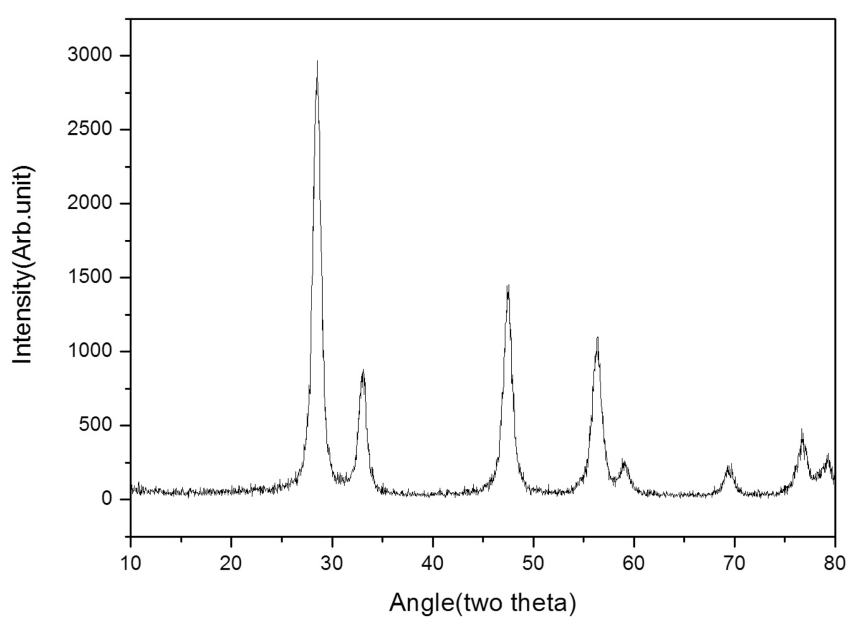

Fig. 1. Typical X-ray diffraction patterns of the ceria nanosphere obtained from cerium acetate precursor in air at $750^{\circ} \mathrm{C}$.

sis such as high solution concentration, short residence time, and high temperature variation results in a more hollow and/or porous structure. ${ }^{10)}$ The morphology of particles is strongly influenced by the preparation condition in spray pyrolysis and, therefore, the research direction in spray pyrolysis has been focused on the control of the particle mor-
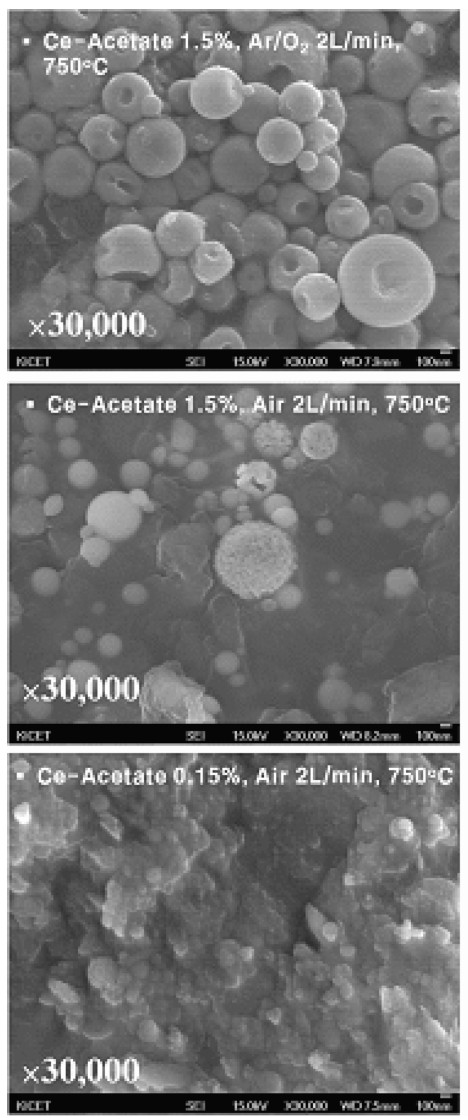
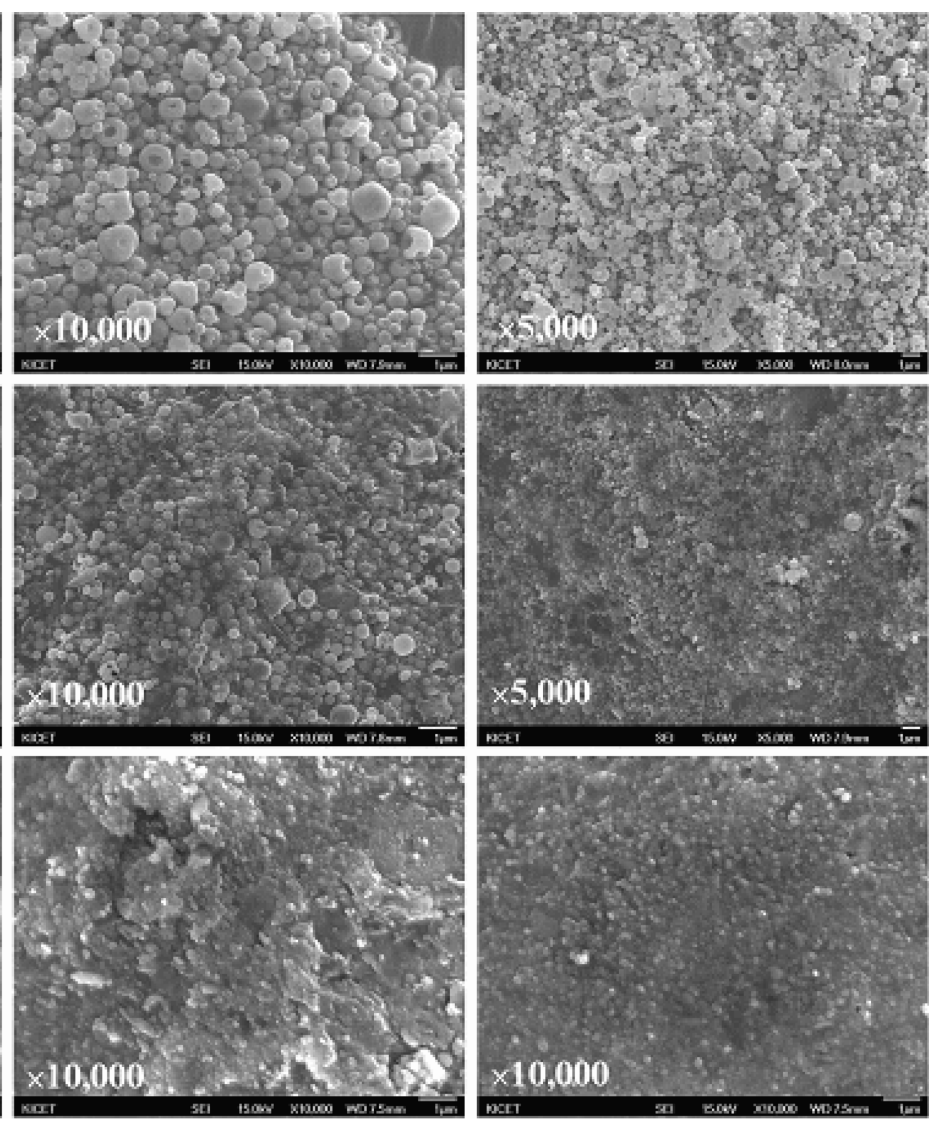

Fig. 2. FE-SEM images for ceria nano-sphere produced from (a) cerium acetate $1.5 \%$ in $\mathrm{O}_{2}$ flowing atmosphere (b)cerium acetate $1.5 \%$ in air (c) cerium acetate $0.15 \%$ in air at $750^{\circ} \mathrm{C}$. Porous agglomerate are found especially for large particles $(>1 \mu \mathrm{m})$. 

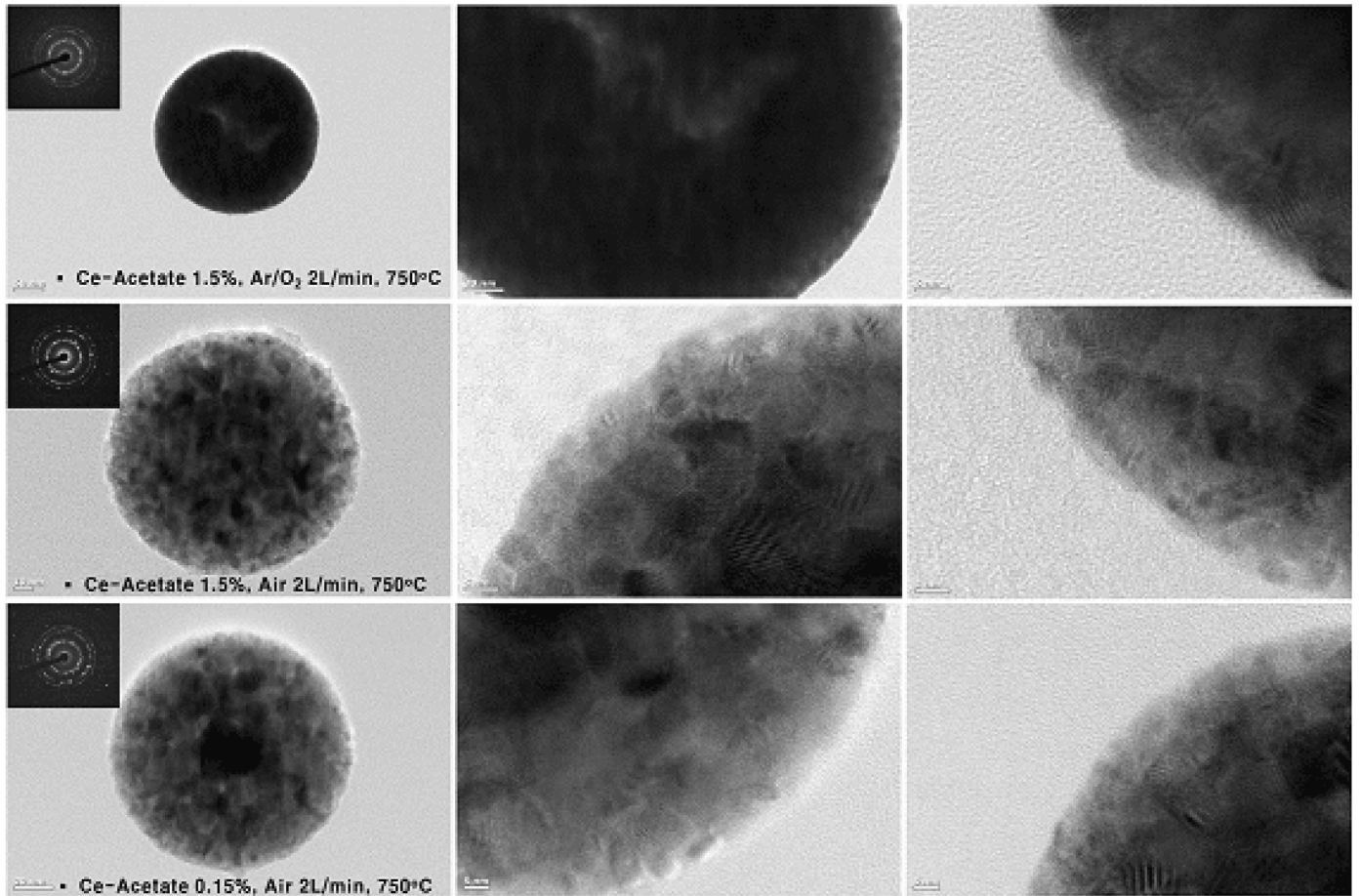

Fig. 3. HRTEM images for ceria nano-sphere from (a) cerium acetate $1.5 \%$ in $\mathrm{O}_{2}$ flowing atmosphere (b)cerium acetate $1.5 \%$ in air (c) cerium acetate $0.15 \%$ in air at $750^{\circ} \mathrm{C}$.

In this work, the particles were prepared under the condition such as low solution concentration, long residence time, and low gas flow rate in order to obtain more solid morphology. The fragility of ceria abrasive was evidently beneficial to scratch performance. However, hollow and fractured nature of the abrasive should reduce the removal rate of CMP slurry as a trade-off. Therefore, appropriate hardness and fracture toughness are required to maintain the removal rate (the polishing rate) without decreasing productivity per unit time of CMP process.

Figure shows the X-ray diffraction patterns of the samples obtained at $750^{\circ} \mathrm{C}$. The pattern is consistent with the characteristic peaks of $\mathrm{CeO}_{2}$ with the $\mathrm{CaF}_{2}$ structure without impurity phase and broad feature of XRD peak implies nano-sized crystallization of ceria occurred. The yellow color of the as-prepared sample also excludes any carbon component remaining inside the particles. It was reported that ceria from aqueous precursor solution exhibits higher crystallinity than from the polymeric precursor solution. ${ }^{11)}$

Fig. 2 shows that crystalline ceria nano-spheres were synthesized through ultrasonic spray pyrolysis of cerium acetate precursor without any doping of metal ion. The ceria prepared in an $\operatorname{Ar}(40 \%) / \mathrm{O}_{2}(60 \%)$ atmosphere at $750^{\circ} \mathrm{C}$ has spherical and solid morphology. The particle size ranged from $100 \mathrm{~nm}$ to $1000 \mathrm{~nm}$ and the mean size was around $300 \mathrm{~nm}$. However, the abrasive prepared in an air flow of $750^{\circ} \mathrm{C}$ (precursor $1.5 \%$ ) showed some porous agglomerated structure for larger particles, which is composed of small nanoparticles with $<10 \mathrm{~nm}$. The abrasive prepared from lower solution concentration $(0.15 \%)$ exhibited a similar particle size and more uniform size distribution. As shown in Fig. 3, when the precursor concentration was changed from $1.5 \%$ to $0.15 \%$, the mean particle size exhibited no significant change $(\sim 130 \mathrm{~nm})$ because the sintering between necked primary particles was determined in the post drying stage. ${ }^{12)}$

The high resolution TEM image (Fig. 3) clearly shows that each particle is non-agglomerated and the shape is close to an ideal nano-sphere. As shown in the HRTEM images, the sample prepared in $\mathrm{Ar} / \mathrm{O}_{2}$ flow shows solid spherical shape, while on the other hand, the ceria prepared in the air stream are porous agglomerates of nanoparticles $(<10 \mathrm{~nm})$, which is not clear in the FE-SEM images. The ceria spheres prepared in air exhibited more porous structure in which primary grains are loosely bound to each other, which is well consistent with the fact that the less dense and agglomerated nano-clusters are more frequently found in FE-SEM (Fig. 2) for a large particle with the size of around $1 \mu \mathrm{m}$.

\section{Conclusion}

The effects of the preparation condition on the morphology of ceria particles were investigated in the ultrasonic spray pyrolysis. In the oxidizing atmosphere, a solid nanosphere was found, whereas less dense and porous structure resulted from the stream of air, which corresponded to relatively large particles in size distribution.

\section{Acknowledgments}

This work was supported by grants from Korea Energy 
Management Corporation(2008-R-RU-02-P-02-3-010) and Small and Medium Business Administration.

\section{REFERENCES}

1. Hitachi Chemical "A Cerium Oxide Particle for the Preparation of a Cerium Oxide Abrasive," PCT/JP 1997/00326; WO 1997/29510.

2. T. TSuzuki, J.S. Robinson, and P.G.J. McCormick, "UVShielding Ceramic Nanoparticles Synthesized by Mechanochemical Processing," J. Austrl. Ceram. Soc., 38 15-19 (2002).

3. E. Tani, M. Yoshimura, and S. Somiya, "Crystallization and Crystal Growth of $\mathrm{CeO}_{2}$ under Hydrothermal Conditions," J. Mater. Sci. Lett., 1 461-62 (1982)

4. A. Bumajdad, M.I. Zaki, J. Eastoe, and L. Pasupulety, "Microemulsion-Based Synthesis of $\mathrm{CeO}_{2}$ Powders with High Surface Area and High-Temperature Stabilities," Langmuir 20 11223-33 (2004).

5. Hitachi Chemical, "Method for Producing Cerium Oxide, Cerium Oxide Abrasive, Method for Polishing Substrate using the same, and Method for Manufacturing Semiconductor Device," PCT/JP 2000/003390; WO 2000/73211.

6. H.Chen and H.Chang, "Synthesis of Nanocrystalline Cerium Oxide Particles by the Precipitation Method," Ceram. Int. 31 795 (2005); F. Zhang, S. Chan, J. E. Spanier, E. Apak, Q.
Jin, R. D. Robinson, and I.g P. Herman, "Cerium Oxide Nanoparticles: Size-selective Formation and Structure Analysis," Appl. Phys. Lett., 80 127-29 (2002).

7. X. Feng, D.C. Sayle, Z.L. Wang, M.S. Paras, B. Santora, A.C. Sutorik, T.X.T. Sayle, Y. Yang, Y. Ding, X. Wang, and Y. Her, "Converting Ceria Polyhedral Nanoparticles into Single Crystal Nano-spheres," Science 312 1504-08(2006).

8. H.Xu, L. Gao, H.C. Gu, and D.S. Yan, "Synthesis of Solid, Spherical $\mathrm{CeO}_{2}$ Particles Prepared by the Spray Hydrolysis Reaction Method," J. Am. Ceram. Soc., 85 139-44(2002).

9. G.L. Messing, S.C. Zhang, and G.V. Jayanthi, "Ceramic Powder Synthesis by Spray Pyrolysis,” J. Am. Ceram. Soc., 76 2707-26 (1993).

10. C.Y. Chen, T.K. Tseng, S.C. Tsai, C.K. Lin, and H.M. Lin, "Effect of Precursor Characteristics on Zirconia and Ceria Particle Morphology in Spray Pyrolysis," Ceram. Int., 34 409-16(2008).

11. H.S. Kang, Y.C. Kang, H.Y. Koo, S.H. Ju, D.Y. Kim, S.K. Hong, J.R. Sohn, K.Y. Jung, and S.B. Park, "Nano-sized Ceria Particles Prepared by Spray Pyrolysis using Polymeric Precursor Solution," Mater. Sci. Eng., B 127 99104(2006).

12. Y.C. Kang and S.B. Park, "Effect of Preparation Conditions on the Formation of Primary ZnO Particles in Filter Expansion Aerosol Generator," J. Mater. Sci. Lett., 16 13133(1997). 